\title{
Social Work Theories and Practice with Battered Women: A Conflict-of-Values Analysis
}

\section{Lorraine M. Gutiérrez}

In the 1970s, wife abuse became a concern of sociologists, feminists, and family theorists. The new perspectives they brought to the problem, which focused more on social factors than on individual pathology, challenged social workers to examine how their practice and assumptions perpetuated the problem. This article investigates how the social work literature has been affected by new theories of domestic violence and analyzes the impact that these theories have had on practice with battered women.

In the early 1970s, it was first recognized that the abuse of hundreds of thousands of women in the United States each year is a social problem that stems from societal norms and institutions that create and perpetuate family violence, rather than a private problem that is caused by the pathology of individuals. This redefinition of wife abuse not only challenged the daily practice and proceedings of social workers, it resurrected such major theoretical issues as the role of professionals in social change efforts and professional values concerning the family. Individual workers were challenged to look at the assumptions behind their practice and examine their role as agents of social control.

In this article, the author examines how this redefinition has been integrated into the social work literature and how it has affected the profession through a review of articles in social work journals. She then uses a conflict-of-values perspective to analyze the process by which these new ideas have influenced the development of social work theories and practice principles in relation to wife abuse. 


\section{REDEFINITION OF BATTERING}

Before 1973, Abstracts for Social Workers (which became Social Work Research and Abstracts in 1977) had no listing for wife abuse, battered women, or family violence. This lack of a separate section of abstracts on this subject implies that although social workers knew about the problem of wife abuse, they did not consider it to be a specific issue or focus for intervention. At that time, the characteristic response to the problem was denial, as Star (1980, p. 340) noted:

... denial is the most widely held defense against acknowledging the prevalence or severity of family violence. We refuse to admit what our senses tell us. . . For example, we actually knew about wife battering at the time of [the] initial investigation of child abuse. The testimony was replete with statements that began, "It was bad enough when he was beating me, but when he started on the children I really became frightened." We only responded to the last part of the sentence; it was ten years before we could acknowledge the first part.

Before the 1970s, wife abuse was analyzed either psychodynamically or as a specific marital style. (Reynolds and Siegle, 1959). The literature suggests that the services offered by social workers treated the battered woman as pathological or as an active participant in her abuse.

Reynolds and Siegle's (1959) article was the only one from this period that directly addressed the problem of marital violence. In that article, the authors analyzed the couples' problems in psychodynamic terms and in relation to how well the couples were performing appropriate social roles and observed (p. 456) that the relationships

. . . seemed to be dominated by their continuing struggle to gain control over each other. The husbands complained that their wives belittled, nagged, bossed, and criticized them and the wives objected strenuously to their husbands leaving them alone, not helping them at home, and not telling them everything. Verbal and physical quarrels were the result.

During the early 1970s, theories were put forth to challenge this psychological view of battering. The proponents of these theories noted that, because of economic and technological developments, 
which occurred throughout this century, the middle-class family has become less important as an economic unit or point of emotional stability; therefore, family theorists began to focus on the individual or interpersonal needs of family members (Demos, 1979). However, as middle-class women continued to enter the work force in increasing numbers and the promarriage norms of previous decades diminished in importance, theorists of all persuations-feminist, liberal, and conservative-began to analyze the changes in the family and the implications of these changes for this society (McGrath, 1979; Thornton and Freedman, 1983; Veroff, Douvan, and Kulka, 1981). This critical analysis of the family, interest in the prevalence of violence in society at large, and the development of feminist theory led to the "discovery" of family violence and attempts to understand it descriptively and analytically (Gelles, 1980).

Both sociological and feminist theories of family violence analyzed how social structures or social conditions led to violence in the family. Sociologists began to look at the role of power in all family interactions, or at how stress from the larger social system or childhood experiences with violence could lead to violence in the family (Gelles, 1980; Goode, 1982). Family violence was no longer considered to be a result of individual pathology or a different conception of marriage; rather, it was thought to develop from stresses, inequalities, and expectations that affect individuals in the family system. As Lystad (1975, p. 339) stated in her review of the social science literature on family violence:

... a comprehensive theory of violence at home must take into account factors at these several levels, placing individual functioning within the social group and within the culture norms by which the group operates. Thus, violence at home occurs when social needs and expectations of the individual are unsupported by either the family or by other social institutions, and when such a mode of expression seems eminently available and legitimate to the individual.

This perspective is typical of most recent sociological theories and research on domestic violence.

The feminist perspective also saw society as the primary cause of family violence, but analyzed wife battering as a form of patriarchal control similar to rape (McGrath, 1979). The power of men over women was considered to be the basis of battering, and patriarchal structures in society were viewed as the reason that most women remained in violent relationships. As Schecter (1982, p. 224) put it: 
In the United States, two dominant conditions of women's lives reinforce male domination and violence in the family. Under capitalism, women are primarily wageless or low paid wage earners and simultaneously, through an unequal division of labor, they are responsible for the maintenance of home and family.

In addition, the feminists noted that because women workers are hampered by higher unemployment, involuntary part-time or seasonal work, fewer pay increases, and lower earnings than men, their increasing participation in the work force has not led to economic independence (see Pearce and McAdoo, n.d.) The economic dependence of women on men and gender-role socialization, which encourages emotional dependence, were identified as factors that set the stage for violence against wives. Thus, abuse was defined as one of the many ways in which mein achieve and maintain control over women (McGrath, 1979).

The transformation of wife abuse from an individual to a social problem challenged social work's psychological view of and responses to domestic violence. No longer were battered women masochistic; they were trapped. Therefore, battering could no longer be treated by individual or couple therapy; rather, a means had to be found for loosening the bonds of women, changing social norms, and creating opportunities for all women. This perspective challenged the profession, for the logical focus was no longer on the individual or the particular family, but on society.

In the mid-1970s, new theories of wife abuse began to appear in the social work literature. As these theories challenged traditional practice, practitioners became interested in new techniques for working with cases of wife abuse. In this article, the impact of these sociological and feminist ideas on the theoretical and practice literature will be analyzed in relation to the following questions:

- To what extent have social work theories of wife abuse been affected by feminist or sociological theories?

- In what ways have these theories influenced proposals for new types of social work practice with battered women?

- How can these suggested changes in theory and practice be analyzed in relation to conflicts in values?

\section{REVIEW OF THE LITERATURE}

\section{Methodology}

One means of studying the profession's view of wife abuse is to analyze how the social work literature has approached the issue. Books and articles describing how social workers could respond to 
wife abuse first appeared in 1973. Because the body of literature is so large, this article will focus only on articles that were published in social work journals from 1973 to 1984 . Although these articles do not constitute an exhaustive sample because 75 percent of them are practice, rather than research, based (Tripodi, 1984), trends in journal articles can indicate how social work theory integrates new ideas into principles for practice.

From 1973 to 1984, thirty-four articles about battered women, domestic violence, or battered women's services were published in the following journals: Administration in Social Work, Child Welfare, Catalyst, Journal of Sociology and Social Welfare, Social Casework, Social Service Review, Social Work, and Social Work Research and Abstracts. Each article was content analyzed and coded according to its theoretical perspective and the type of intervention that was suggested. Theoretical perspectives were coded according to whether they took a psychological, sociological, or feminist perspective of battering using the following criteria:

Psychological. Personality factors were identified as the primary cause of battering. Because psychological theories are concerned primarily with individual differences, they assume that the origin of wife abuse is more within individuals than in society.

Sociological. Environmental factors, such as stress, family systems, or intergenerational learning, were presented as the primary causes of family violence. This view also assumes that a social consensus supports the perpetuation of the family system and that social conflict or power relationships do not play a major role in creating family violence (Yorburg, 1983).

Feminist. Gender roles and patriarchal attitudes were described as creating and perpetuating violence, and battering was considered to be a form of social oppression. This perspective assumes that wife abuse is a form of social control.

The articles were also analyzed according to the type of intervention they proposed. The range of responses was categorized as follows: (1)individual-level responses (individual, group, or family counseling), (2) community-level responses (consciousness raising of service providers, advocacy, coordination of services, or community education), and (3) society-level responses (the development of specialized programs, research, legal reforms, new social policies, or widespread social change).

\section{Results}

In relation to the first question, to what extent have social work theories been affected by feminist or sociological theories? The author identified the following trends from 1973 to 1984: 
TABLE 1. Theoretical Perspectives of Authors, by Years of Publication

\begin{tabular}{lccccc}
\hline & \multicolumn{4}{c}{ Years of Publication } & \\
\cline { 2 - 5 } Perspective & $1973-75$ & $1976-78$ & $1979-81$ & $1982-84$ & Total \\
\hline Psychological & 2 & 1 & 1 & 0 & 4 \\
Sociological & 0 & 2 & 4 & 8 & 14 \\
Feminist & 0 & 6 & 8 & 2 & 16 \\
Total & 2 & 9 & 13 & 10 & 34 \\
\hline
\end{tabular}

1. The thirty-four articles reflected all three perspectives on family violence.

2. There were more feminist (sixteen articles) and sociological analyses (fourteen articles) than psychological analyses (four articles).

3. Sociological theories have been the predominant mode of analysis since 1981 (see Table 1).

No one psychological theory was presented in the literature during that time; all the psychological theories assumed that violent behavior is caused by underlying personality factors. For example, although Field and Field (1973, p. 238) described the barriers encountered by battered women who seek criminal prosecution or civil protection, they stated that what these women need is casework by "those whose responsibility it is to help understand and ease pathological mental processes, and the conflicts peculiar to marriage." Others, such as Elbow (1977) and Moore (1975), indicated that domestic violence fulfills the unconscious needs or goals of both the batterer and the victim.

Sociological perspectives in the social work literature center on theories of the cycle of violence and stress. These theories consider battering to be a result of the interaction of childhood experiences of violence, which lead to violent behavior as a learned response to frustration, with present stresses in the family system. Because sociological theories emphasize stress factors, they assume that domestic violence is more prevalent among poor families who are apt to experience chronic stress because of financial hardships (Gelles, 1980). Furthermore, they utilize knowledge of how social factors can create family violence, but they do not challenge the basic structure of society.

The articles with this perspective focused on how personalities are shaped by the environment, rather than on the nature of the environmental stressors or on mechanisms of effective coping. For example, in their study of fifty-seven women in women's shelters 
in Arizona and California, Star et al. (1979) administered five psychosocial and personality profiles in an attempt to determine the psychosocial aspects of wife abuse. Although they found that "battered women in this sample fell solidly within the average range on most of the personality and clinical factors measured" (p. 483), they concentrated on the nine factors on which the women differed-not on the high levels of violence and disruption that these women had survived. The article by Star et al., as well as other articles, suggests that many caseworkers may be adopting sociological theories and discarding psychological theories of battering (see Ball, 1977; Bern, 1981; Carlson, 1977, 1984; Edelson, 1984; Elbow, 1982; Hendricks-Matthews, 1982; Peterson, 1980; Saunders, 1984).

Feminist theories were the basis of many of the articles surveyed. The following analysis by Pfouts $(1978$, p. 101) is representative of the feminist viewpoint:

It was only when the problem was defined by feminists in terms of power, culture, and social structure that the plight of the abused wife came into sharper focus. It is now understood more clearly that a wife must endure abuse not because she enjoys it, but because the culture has taught her that she is somehow to blame for her predicament, and because the society makes it difficult for her to do anything about it.

Central to many of these articles is a critique of how social workers have treated battered women and their role in perpetuating family violence. For example, Nichols (1976, p. 57) stated:

... caseworkers rarely pick abusiveness as the focus of intervention; rather they tend to ignore this symptom. The position caseworkers take often supports a belief that the wife encourages, provokes, or even enjoys abusive treatment.

And McShane (1979, p. 38) noted:

Reports have shown that insensitive responses and inadequate information given to women as they first reach out may cause them to remain in abusive situations for years.

The authors of these articles do not blame individual agencies and caseworkers for the treatment given to battered women; rather, they perceive that the treatment arises from structures or systems 
in the society that cause services to be fragmented or that reinforce patriarchy (Bass and Rice, 1979; Sullivan, 1980) Therefore they believe that battered women and the agencies that serve them are subject to the same values and inequities that create family violence.

In sum, sociological and feminist theories seem to be replacing psychological theories of wife abuse. Feminist theories transformed the analysis of battering by taking the onus of responsibility for the problem from the individual and attributing it to social conditions. Hence, in the articles with a feminist perspective, battered women were no longer presented as pathological; rather, they were viewed as behaving in accordance with the limitations placed on them by a patriarchal society.

In the fourteen articles with a sociological perspective, however, the transformation was not as great. Even though battering couples were rarely depicted as deviant and were presented as reacting to social conditions and learned behavior, the role of power and control in creating wife abuse and in limiting women's options was rarely presented as a crucial dynamic of the abusive family system. That is, the focus of these articles was on individual development and behavior, rather than on the role of battering in controlling women or on how social institutions are mechanisms of social control.

In relation to the second question, In what way have these theories influenced suggestions for social work with battered women? The articles were analyzed according to the type of intervention that was proposed and how closely the targets of intervention corresponded with the theoretical perspective of the authors. Most authors suggested more than one response to battering; Table 2 (p. 44) demonstrates the different types of intervention suggested by authors with different theoretical orientations. In general, authors with a psychological perspective were apt to suggest individual responses, authors with a sociological view tended to suggest individual or community responses, and authors with a feminist orientation were likely to suggest community or societal interventions.

The majority of the authors with a psychological orientation proposed a form of casework that would work toward ending violence in the family and helping the partners to develop new ways of interacting. Since they considered that battering is caused by individual characteristics, their focus was often on long-term casework rather than on crisis intervention. Cantoni's (1981, p. 12) explanation is an example: 
Treatment of the violence-prone family is accomplished through the therapeutic relationship. Clients are given support and nurture by a caring worker with whom they experience a new way of interacting. Clients gain some understanding of the dynamic interactions between themselves and family members so that they recognize those aspects of their family systems needing change.

Authors with this perspective also recommended family or marital counseling, with the goal of maintaining the family system-an approach that is consistent with traditional social work practice (Bograd, 1984; Libow, Raskin, and Caust, 1982). Because the individual was their primary target of analysis and intervention, these authors were the most consistent in the theory they expounded and the level of intervention they proposed.

Many of the articles with a sociological orientation suggested both individual- and community-level interventions. The focus on individual-level interventions is consistent with the theoretical position of these articles, which tended to present sociological theories as a means of understanding the individual abuser or victim. Although sociological theories of domestic violence consider society to be the origin of violence in that it causes stress and accepts violent behavior, the focus of individual interventions was not on how these stresses or norms could be eliminated, but on how individuals or families could learn new patterns of coping. As Holmes (1982, p. 594) stated: “Our task is not simply to help

TABLE 2. Levels of Intervention Proposed by Authors in the Three Perspectives

\begin{tabular}{|c|c|c|c|c|}
\hline \multirow[b]{2}{*}{ Perspective } & \multicolumn{3}{|c|}{ Level of intervention } & \multirow{2}{*}{$\begin{array}{l}\text { Total number of } \\
\text { proposals for } \\
\text { each perspective }\end{array}$} \\
\hline & Individual & Community & Society & \\
\hline $\begin{array}{c}\text { Psychological } \\
\text { (4 articles) }\end{array}$ & 8 & 1 & 1 & 10 \\
\hline $\begin{array}{l}\text { Sociological } \\
\text { (14 articles) }\end{array}$ & 16 & 14 & 8 & 38 \\
\hline $\begin{array}{l}\text { Feminist } \\
\text { (16 articles) }\end{array}$ & 6 & 21 & 10 & 37 \\
\hline $\begin{array}{l}\text { Total number } \\
\text { of interventions }\end{array}$ & 30 & 36 & 19 & 85 \\
\hline
\end{tabular}

a The totals add up to more than 34 because most authors suggested more than one intervention. 
families deal with violence within, but to strengthen their capabilities to deal with pressures toward violence that impact on the community."

The intervention strategies suggested by these authors included assessing the level of violence in the family, responding to the immediate crisis, advocating with legal/criminal justice agencies, and coordinating services (McEvoy, Brookings, and Brown, 1983; Star, 1980). Many of the individual approaches presented by these authors differed from those of the psychologically oriented authors in that they emphasized crisis intervention and protecting the woman from future violence, rather than long-term family-oriented treatment.

Although almost half the thirty-four articles took a feminist perspective, which defined social forces as the cause of domestic violence, societal changes accounted for only nineteen of the eighty-five interventions proposed. Most of the articles with a feminist orientation suggested community-level changes, such as improved networking, case coordination, and community education or the development of local coalitions, as the most appropriate interventions. The authors presented these strategies as a means of preventing the "secondary victimization" of battered women by insensitive or hostile service providers (Davis, 1984; Davis and Carlson, 1981; Flynn, 1977; Galper and Washburne, 1977; McNeely and Jones, 1980; Munson, 1980; Pfouts and Renz, 1981; “Violence in the Family"). The articles that combined a feminist analysis with an individual-level intervention suggested casework that would focus on advocating for the woman and connecting her with women's organizations (Berlin and Kravitz, 1981; Constantino, 1981; Nichols, 1976; Schuyler, 1976). For the most part, social workers were not encouraged to work toward larger social changes as much as toward local reforms or changing their daily practice.

This analysis of interventions suggests that the redefinition of battering has affected practice in a paradoxical way; although feminist and sociological theories encouraged social workers to place the responsibility for battering on society, the individual, family, or local community, rather than society, was most often suggested as the locus of change. Although the authors encouraged social workers to take the violence more seriously, the types of interventions they suggested involved the protection of individuals rather than strategies for eliminating violence. The remainder of this article discusses this paradox and how it reflects conflicts that are inherent in the profession. 


\section{CONFLICTING VALUES AND WIFE ABUSE}

Authors who have looked at the interaction between the ideals of social change and the theories of social work have highlighted the difficulty of integrating social change into practice. Rothman (1985) described the conflict that arose during the development of the profession between the modality of casework and the modality of social reform. He stated that because casework theories and practice were more compatible with the common cultural values, they were supported by those in power. In contrast, social reform programs and ideas have been influential only during times of crisis, such as the Depression or the War on Poverty, when prevailing practices seemed ineffective.

Analyses of the feminist influence on social work have recognized the predominance of casework but have noted how the liberal ideology of most social workers impedes work toward social change (Abramowitz, 1978; Becker, 1976; Valentich and Gripton, 1984; Wetzel, 1986; Withorn, 1984). They have observed that the integration of feminist ideas into social work education and practice would require a commitment to changes in the social structure. Therefore, although feminist theories may be reflected in the literature, suggestions for feminist practice rarely occur (Berlin and Kravitz, 1981).

Analyzing social values can be another way of understanding the adoption of new social policies and new practice strategies. Social psychologists have defined values as general and enduring standards that can be used to evaluate past behavior or to guide future actions (Kinder and Sears, 1985). Many scholars, from political scientists to psychologists, have investigated the impact of American values on social welfare policies and have demonstrated that the values of efficiency, individualism, or egalitarianism have been particularly influential (Gurin, Gurin, and Morrison, 1978; Hofstadter, 1948; Okun, 1975; Ryan, 1971).

Tropman (1984) proposed a theory of how value systems influence social welfare policies. He noted that the seven dimensions of values, which are the focal points of the American culture, are learned in conflicting dominant and subdominant pairs (see Table 3). Each pair presents a dilemma because the full expression of either value would be unacceptable in this society. For example, on the dimension of independence, policies that focus totally on selfreliance would prevent the provision of public education. Therefore, the pairing of values acts as a regulating mechanism to orga- 
TABLE 3. American Value Dilemmas

\begin{tabular}{lll}
\hline Dimensions & Dominant values & $\begin{array}{l}\text { Subdominant } \\
\text { values }\end{array}$ \\
\hline Work & Career & Job \\
Social mobility & Contest & Sponsorship \\
Status & Achievement & Equality \\
Independence & Self-reliance & Interdependence \\
Individualism & Inner direction & Other direction \\
Moralism & Permission & Control \\
Ascription & Performance & Quality \\
\hline
\end{tabular}

Source: J. Tropman, "American Values and Social Welfare: Cultural Dissonance in American Society," p. 14. Unpublished manuscript, 1984.

nize and focus thought and to ensure that values will be expressed in appropriate ways.

Each pair is made up of dominant and subdominant values. The expression of values is a function of the tension within and between the pairs, disappointment with prevailing values, or changes in the social system. Although subdominant values are not as strongly held, the development and maintenance of social services are often dependent on their expression (Tropman, 1984; Tropman, 1986).

The tension that is inherent in this model suggests how social policies and social work practice are affected by values. When dominant values are predominant, it will be difficult to develop and implement programs that reflect subdominant values. During periods of social change, a cultural lag may occur, which may call into question the dominant values and may make the emergence of less "legitimate" programs more feasible. This conceptual framework may also help one understand how social services for battered women have evolved.

In reviewing the literature on these central dimensions of values, it appears that the new theories of wife abuse specifically challenged the existing values of individualism and moralism. Both sociological and feminist theories reconsidered the locus of control for battering and the degree to which battering was permissible. These became crucial issues for the development of theories and the delivery of services.

The conflict in values surrounding individualism focuses on the issues of inner and other direction: the degree to which individuals are in control of their environment. The dominant value-inner 
direction-stresses that the individual is in control and can master the environment; the subdominant value-other directionstresses that external factors can control individuals and prevent them from achieving their goals. The psychological, sociological, and feminist perspectives on battering consider this issue differently.

The psychological perspective is compatible with the dominant value of inner direction in that it emphasizes the individual and considers wife abuse to arise from personal (internal), rather than societal, causes. Because both the abusive and the abused spouses are viewed as being subject to unconscious forces that are causing their problem, their goal is to achieve a state of inner direction. Therefore, according to this perspective, external forces would have little influence on the lives of healthy individuals.

Feminist theories are focused on the subdominant value of other direction and therefore are incompatible with the dominant culture. They view the actions of the abuser and abused as reflecting social norms and social resources and consider changes in the social structure that would support alternative behaviors and resources to be the only solution to wife abuse. Individuals alone are thought to have little impact on external structures, and collective action is suggested for bringing about desired changes (Schecter, 1982).

Sociological theories stand somewhere in between the psychological and the feminist theories. Although the etiology of wife abuse is thought to be such external forces as stress and learned behavior, the goal is to help the abuser and the abused learn to withstand the stress and behave differently-that is, to be more inner directed and less other directed. Thus, corrective measures include programs that teach batterers more appropriate ways of reducing stress (Saunders, 1984) or that teach victims to advocate for themselves (Weitzman and Dreen, 1982). This perspective is compatible with the dominant social value of inner direction because inner direction is the goal of treatment, no matter what is causing the problem.

Conflicts regarding moralism center on the degree to which wife abuse should be permitted or controlled. Permission and freedom of expression have been the dominant values although control and judgments about the right way to behave have also been prevalent. For example, law enforcement agencies have not intervened in family issues, despite laws to the contrary; their inaction has permitted the occurrence of violent behavior in the privacy of the family (Munson, 1980). Similarly, the training of social workers to 
be nonjudgmental and nondirective and to accept a client's definition of his or her behavior has led social workers to accept violent behavior.

Psychological theories have not directly addressed the issue of permission versus control. Their silence on this issue suggests that although they may view wife abuse as unacceptable, they do not consider that it is the role of the worker to control it or that its amelioration should be a focus of intervention. Furthermore, their silence may reflect the belief that violence meets the unconscious needs of both the abuser and the victim and therefore that control is not possible until the underlying problems are addressed. This perspective is compatible with the dominant value that treats familial behaviors as permissible as long as they do not affect persons outside the family.

Both sociological and feminist theories take a clear stand on this issue. Not only do they view wife abuse as not permissible, they believe it should be controlled by law enforcement agencies and treated as any other assault. However, once a case of wife abuse is in the hands of the law, these perspectives differ. Sociological theories are more apt to suggest that the force of the law can be used to motivate abusers to enter treatment (Holmes, 1981), whereas feminist theories stress that incarceration may be the only way to stop battering until changes in the social system occur (Sullivan, 1982). Therefore, sociological theories are more compatible than feminist theories with the dominant value of permission, while both advocate high levels of control.

\section{CONCLUSION}

This analysis of the dimensions of individualism and moralism suggests why sociological theories seem to be prevailing over psychological and feminist theories of wife abuse. Although psychological theories are most compatible with the dominant values, they conflict with the subdominant values held by social workers because they place little importance on external factors. Conversely, feminist theories are so firmly grounded in subdominant values that they may be threatening to a profession that aspires to legitimacy and for which casework is the primary mode of practice. Sociological theories, which incorporate the effect of external factors on individuals without threatening the dominant value of inner direction, allow social workers to integrate the new theories of wife abuse without changing their locus, or focus, of practice. Therefore, although some aspects of the nature of practice have 
changed, the target has not. The question remains whether social workers can work toward both social and individual change.

\section{REFERENCES}

Abramowitz, M. “Social Work and Women's Liberation: A Mixed Response." Catalyst, 1 (1978), pp. 91-103.

Ball, M. "Issues of Violence in Family Casework." Social Casework, 58 (January 1977), pp. 3-12.

Bass, D., and Rice, J. "Agency Responses to the Abused Wife." Social Casework, 60 (June 1979), pp. 338-342.

Becker, R. "The Attitudes of Social Workers toward National Health Insurance." Unpublished Ph.D. dissertation, University of Denver, 1976.

Berlin, S., and Kravitz, D. "Women as Victims: A Feminist Social Work Perspective." Social Work, 26 (November 1981), pp. 447-449.

Bern. E. "From Violent Outbreak to the Spouse Abuse Syndrome." Social Casework, 63 (January 1982), pp. 41-45.

Bograd, M. "Family Systems Approaches to Wife Battering: A Feminist Critique." American Journal of Orthopsychiatry, 54 (October 1984), pp. 558568.

Cantoni, L. "Clinical Issues in Domestic Violence." Social Casework, 62 (January 1981), pp. 3-12.

Carlson, B. "Battered Women and Their Assailants." Social Work, 22 (November 1977), pp. 455-460.

. "Causes and Maintenance of Domestic Violence: An Ecological Analysis." Social Service Review, 58 (December 1984), pp. 569-587.

Constantino, C. "Intervention with Battered Women: The Lawyer-Social Worker Team." Social Work, 26 (November 1981), pp. 456-460.

Davis, L. "Beliefs of Service Providers about Abused Women and Abusing Men." Social Work, 29 (May-June 1984), pp. 243-250.

Davis, L., and Carlson, B. "Attitudes of Service Providers toward Domestic Violence." Social Work Research and Abstracts, 17 (Winter 1981), pp. 34-35.

Demos, J. "Images of the American Family: Then and Now." In Changing Images of the American Family, edited by V. Tufte and B. Myerhoff, pp. 44 60. New Haven, Conn.: Yale University Press, 1979.

Edelson, J. "Working with Men Who Batter." Social Work, 29 (May-June 1984), pp. 237-242.

Elbow, M. "Children of Violent Marriages: The Forgotten Victims." Social Casework, 63 (October 1982), pp. 465-471.

. "Theoretical Considerations of Violent Marriages." Social Casework, 58 (November 1977), pp. 515-526.

Field, M., and Field, H. "Marital Violence and the Criminal Process: Neither Justice nor Peace." Social Service Review, 47 (June 1973), pp. 221240.

Flynn, J. "Recent Findings Related to Wife Abuse." Social Casework, 58 (January 1977), pp. 13-20.

Galper, M., and Kott Washburne, C. "Maximizing the Impact of an Alternative Agency." Journal of Sociology and Social Welfare, 4 (November 1977), pp. 248-257.

Gelles, R. "Violence in the Family: A Review of the Research in the 
Seventies." Journal of Marriage and the Family, 42 (November 1980), pp. 143-155.

Goode, W. The Family, 2nd ed. Englewood Cliffs, N.J.: Prentice-Hall, 1982.

Gurin, P., Gurin, G., and Morrison, B. "Personal and Ideological Aspects of Internal and External Control." Social Psychology, 41 (December 1978), pp. 275-296.

Hendricks-Matthews, M. "The Battered Woman: Is She Ready for Help?" Social Casework, 63 (March 1982), pp. 131-137.

Hofstadter, R. The American Political Tradition. New York: Vintage Books, 1948.

Holmes, S. "A Holistic Approach to the Treatment of Violent Families." Social Casework, 62 (December 1981), pp. 594-600.

Kinđer, D. R., and Sears, D. O. "Public Opinion and Political Action." In The Handbook of Social Psychology, 3rd ed., edited by G. Lindsey and E. Aronson, vol. 2, pp. 659-726. New York: Random House, 1985.

Libow, J., Raskin, P., and Caust, B. "Feminist and Family Systems Therapy: Are They Irreconcilable?" American Journal of Family Therapy, 10 (Fall 1982), pp. 3-12.

Lystad, M. "Violence at Home: A Review of the Literature." American Journal of Orthopsychiatry, 45 (April 1975), pp. 328-345.

McEvoy, A., Brookings, J., and Brown, C. "Responses to Battered Women: Problems and Strategies." Social Casework, 64 (February 1983), pp. 92-96.

McGrath, C. "The Crisis of Domestic Order." Socialist Review, 43 (1979).

McNeely, R., and Jones, J. "Refuge from Violence: Establishing Shelter Services for Battered Women." Administration in Social Work, 4 (Winter 1980), pp. $71-82$.

McShane, C. "Community Services for Battered Women." Social Work, 24 (January 1979), pp. 34-39.

Moore, J. "Yo-yo Children: Victims of Matrimonial Violence." Child Welfare, 54 (September-October 1975), pp. 557-566.

Munson, P. "Protecting Battered Wives: The Availability of Legal Remedies." Journal of Sociology and Social Welfare, 7 (July 1980), pp. 586-600.

Nicols, B. "The Abused Wife Problem." Social Casework, 57 (January 1976), pp. 27-32.

Okun, A. Equality and Efficiency: The Big Tradeoff. Washington, D.C.: The Brookings Institution, 1975.

Pearce, D., and McAdoo, H. Women and Children: Alone and in Poverty. Washington, D.C.: Policy Institute, School of Law, Catholic University of America, n.d.

Peterson, R. "Social Class, Social Learning, and Wife Abuse." Social Service Review, 54 (September 1980), pp. 390-406.

Pfouts, J. "Violent Families: Coping Responses of the Abused Wife." Child Welfare, 57 (February 1978), pp. 101-110.

Pfouts, J., and Renz, C. "The Future of Wife Abuse Programs." Social Work, 26 (November 1981), pp. 451-455.

Reynolds, R., and Siegle, E. "A Study of Casework with Sado-masochistic Marriage Partners." Social Casework, 40 (December 1959), pp. 545-551.

Rothman, G. Philanthropists, Therapists, and Activists: A Century of Ideological Conflict in Social Work. Cambridge, Mass.: Schenkman Publishing Co., 1985.

Ryan, W. Blaming the Victim. New York: Vintage Books, 1976. 
Saunders, D. "Helping Husbands Who Batter." Social Casework, 65 June 1984), pp. 347-353.

Schecter, S. Women and Male Violence. Boston: South End Press, 1982.

Schuyler, M. "Battered Women: An Emerging Social Problem." Social Work, 21 (November 1976), pp. 488-491.

Star, B. "Patterns in Family Violence." Social Casework, 61 (June 1980), pp. 339-346.

Star, B., et al. "Psychosocial Aspects of Wife Battering." Social Casework, 60 (October 1979), pp. 479-487.

Sullivan, G. "Cooptation of Alternative Services: The Battered Women's Movement as a Case Study." Catalyst, 4 (1982), pp. 39-56.

Thornton, A., and Freedman, D. "The Changing American Family." Population Bulletin, 38 (October 1983), pp. 3-43.

Tripodi, T. "Trends in Research Publication: A Study of Social Work Journals from 1956 to 1980." Social Work, 29 (July-August 1984), pp. 353-359.

Tropman, J. "American Values and Social Welfare: Cultural Dissonance in American Society." Unpublished manuscript, 1984.

- Conflict in Culture: Permission vs. Controls and Alcohol Use in American Society. Lanham, Md.: University Press of America, 1986.

Valentich, M., and Gripton, J. "Ideological Perspectives on the Sexual Assault of Women." Social Service Review, 58 (September 1984), pp. 448461.

Veroff, J., Douvan, E., and Kulka, R. The Inner American. New York: Basic Books, 1981.

"Violence in the Family." Editorial, Social Casework, 58 (January 1977), pp. 50-51.

Weitzman, J., and Dreen, K. "Wife Beating: A View of the Marital Dyad." Social Casework, 63 (May 1982), pp. 166-173.

Wetzel, J. W. "The Feminist World View Conceptual Framework." Social Casework, 67 (March 1986), pp. 166-173.

Withorn, A. Serving the People: Social Services and Social Change. New York: Columbia University Press, 1984.

Yorburg, E. Families and Societies. New York: Columbia University Press, 1983.

Lorraine M. Gutiérrez is a graduate student and teaching assistant, Women's Studies Program, University of Michigan, Ann Arbor. 